\title{
The Autism Birth Cohort (ABC): a study of autism spectrum disorders in MoBa
}

\author{
Pål Surén ${ }^{\mathrm{a}, \mathrm{b}}$, Synnve Schjølberg ${ }^{\mathrm{a}}$, Anne-Siri Øyen ${ }^{\mathrm{a}, \mathrm{c}}$, Kari Kveim Lie ${ }^{\mathrm{a}}$, Mady Hornig ${ }^{\mathrm{d}}$, \\ Michaeline Bresnahan $^{\mathrm{d}, \mathrm{e}}$, Therese Bakke ${ }^{\mathrm{a}}$, Christine Roth ${ }^{\mathrm{a}, \mathrm{c}}$, Elin Alsaker ${ }^{\mathrm{a}}$, Patricia Schreuder ${ }^{\mathrm{a}}$, \\ Nina Stenberg ${ }^{\mathrm{a}, \mathrm{c}}$, Ted Reichborn-Kjennerud ${ }^{\mathrm{a}, \mathrm{f}}$, Deborah Hirtz $^{\mathrm{g}}$, Ezra Susser ${ }^{\mathrm{d}, \mathrm{e}}$, Per Magnus ${ }^{\mathrm{a}}$, \\ W. Ian Lipkin ${ }^{\mathrm{d}}$ and Camilla Stoltenberg ${ }^{\mathrm{a}, \mathrm{h}}$ \\ a) Norwegian Institute of Public Health, Oslo/Bergen, Norway \\ b) National Center for Epilepsy, Oslo University Hospital, Oslo, Norway \\ c) Nic Waals Institute, Lovisenberg Hospital, Oslo, Norway \\ d) Mailman School of Public Health, Columbia University, New York, NY, USA \\ e) New York State Psychiatric Institute, New York, NY, USA \\ f) Institute of Psychiatry, University of Oslo, Oslo, Norway \\ g) National Institute of Neurological Disorders and Stroke, Bethesda, MD, USA \\ h) Department of Public Health and Primary Health Care, University of Bergen, Bergen, Norway \\ Correspondence: Pål Surén, Norwegian Institute of Public Health, P.O. Box 4404 Nydalen, NO-0403 Oslo, Norway \\ E-mail: pal.suren@fhi.no Telephone: (+47) 92898631
}

\begin{abstract}
Background: Autism spectrum disorders (ASDs) are characterized by persistent deficits in social communication and interaction and restricted, repetitive patterns of behavior, interests or activities. In most cases, the cause of ASD is likely to be a combination of genetic predisposition and environmental exposures occurring in fetal life or early infancy. Consequently, a prospective pregnancy cohort like MoBa represents an ideal platform for studies of ASDs in children.

Methods: The Autism Birth Cohort (ABC) Study has identified potential ASD cases in MoBa through questionnaire-based screening, parental and professional referrals, and linkages to the Norwegian Patient Register. ASD diagnoses have been ascertained through in-person clinical assessments and medical record reviews.

Current results: By the end of 2012, the ABC Study had identified 518 ASD cases in MoBa. The ASD prevalence in school-age children is $0.7-0.8 \%$, which is in line with nationwide estimates for Norway. The most important source of ASD case identification was registry linkages, while only a minority was detected through early screening. Published findings show that screening at 18 months misses the majority of ASD cases. Analyses of risk factors for ASDs have shown that maternal use of folic acid supplements in early pregnancy may lower the child's risk of developing ASDs and that paternal obesity appears to increase the child's risk of ASDs.

Future plans: ASD case identification will continue through annual registry linkages and subsequent reviews of medical records. Analyses of plasma samples and RNA samples will be conducted to investigate prenatal and perinatal microbial exposures, innate immune and inflammatory responses, biomarkers of autism risk, and exposures to xenobiotics. Analyses of deciduous teeth will also investigate the effect of medications and environmental toxins. Exome sequencing of DNA from ASD cases and their parents is ongoing, and will elucidate the role of de novo DNA mutations in the pathogenesis of ASDs. Future epidemiological analyses will explore the results of the 36-month screening for ASDs, the diagnostic stability and developmental trajectories in ASD children, and psychiatric and medical comorbidities in ASDs.
\end{abstract}

This is an open access article distributed under the Creative Commons Attribution Licence, which permits unrestricted use, distribution, and reproduction in any medium, provided the original work is properly cited.

\section{PURPOSE OF THE ARTICLE}

The purpose of this article is to describe the Autism Birth Cohort (ABC) Study, the sub-study of autism spectrum disorders (ASDs) in MoBa. We start by providing background information about ASDs, as this is necessary to explain why a prospective pregnancy cohort is an excellent platform for studies of ASDs in children. We then describe how the ABC Study has been managed and conducted, what the current results are, and what plans we have for the future of the study.

\section{AUTISM SPECTRUM DISORDERS (ASDS): BACKGROUND}

\section{Clinical features}

Autism spectrum disorders (ASDs) constitute a heterogeneous group of neurodevelopmental disorders defined by (1) persistent deficits in social communication and social interaction across multiple contexts and (2) restricted, repetitive patterns of behavior, interests or activities (1). Symptoms of autism may vary in severity and time of onset, and children with ASDs display 
a wide range of cognitive skills, from high intelligence to profound mental retardation (2). Around 50\% have intellectual disability (IQ below 70), although the exact proportion is uncertain (2). ASDs are diagnosed according to the Diagnostic and Statistical Manual of Mental Disorders (Fifth Edition) (DSM-5) (1) or the International Classification of Diseases (10th Revision) (ICD-10) (3). The DSM classification is used in clinical practice in North America and is the basis for research-standard diagnoses of ASDs. The DSM-5 was introduced in 2013 to replace the DSM-IV(4), which was used from 1994-2013. The ICD-10 is the standard classification system used in clinical practice in Europe and employs the term "pervasive developmental disorders" (PDDs) for ASDs. The research-standard instruments for diagnosis of ASDs are the Autism Diagnostic Interview - Revised (ADI-R) (5) and the Autism Diagnostic Observation Schedule, Second Edition (ADOS2) (6). The ADI-R is a parent interview, whereas the ADOS is a semi-structured, standardized assessment of the child's social interaction, communication, and imaginative play. Both instruments are now widely used in both research and clinical practice.

The concept of autism as a developmental disorder was introduced by Leo Kanner in his article about children with "inborn autistic disturbances of affective contact" in 1943 (7) and by Hans Asperger in his case series with descriptions of "autistic psychopathy" in children in 1944 (8). Throughout the 1950s and 1960s, the condition was usually referred to as "childhood schizophrenia", and it was not established as a separate diagnostic entity until the advent of the DSM-III classification in 1980 (9). The DSM-III used the term "infantile autism", but in 1994, this was replaced by "autistic disorder" in the DSM-IV (4). Autistic disorder was defined as a disorder involving three domains: (1) impairment in social interaction, (2) impairment in communication, and (3) restricted, repetitive and stereotyped patterns of behavior, interests and activities (4). The DSM-IV also introduced two other subtype diagnoses of autism: Asperger's disorder and "pervasive developmental disorder not otherwise specified" (PDD-NOS). Asperger's disorder differed from autistic disorder in that there was no significant early delay in language acquisition (4). PDD-NOS was used for children who displayed impairments in reciprocal social interaction and symptoms within one of the other domains, but who did not meet the criteria for autistic disorder or Asperger's disorder (4). PDD-NOS was regarded to be a sub-threshold diagnosis in relation to the two others, in the sense that individuals with this diagnosis were less severely affected by the core symptoms of autism (4). The ICD-10 uses the terms "childhood autism" for autistic disorder, "Asperger syndrome" for Asperger's disorder, and "atypical autism", "other PDD" or "unspecified PDD" for PDDNOS.

There was substantial clinical overlap between the ASD subtype diagnoses of the DSM-IV. There was also wide variability in clinical presentation within the subtypes, and they were found to have low reliability across assessment sites (10). The subtype diagnoses did not convey any information about other clinically relevant characteristics such as cognitive function and language level. All of these limitations led to the removal of the subtype diagnoses from the DSM-5 in 2013 (1). The ASD diagnosis of the DSM-5 is meant to be more informative by requiring that the diagnosis be accompanied by specifications of: (1) symptom severity on a scale from 1 to 3 , (2) whether or not intellectual disability is present, (3) whether or not language impairment is present, (4) known medical or genetic conditions or environmental factors likely to have been involved in the pathogenesis, (5) other coexisting neurodevelopmental, mental or behavioral disorders, and (6) whether or not catatonia is occurring (1). A new version of the ICD is scheduled for 2015, and this will most likely also remove the subtype diagnoses of ASDs (11).

Several screening instruments for ASDs have been developed, and early screening for ASDs is widely recommended. Guidelines from the American Academy of Pediatrics state that all children should be screened for ASDs at age 18 months (12). However, none of the currently available screening instruments have been evaluated in large population-based samples of young children, and the effectiveness of early screening is debated (13).

\section{Prevalence}

The prevalence of diagnosed ASDs has increased rapidly in most developed countries over the past 20 years, and is still increasing. The main cause appears to be changing diagnostic practices, with more children with lighter symptoms now receiving ASD diagnoses (14). However, a genuine increase in the occurrence of ASDs cannot be ruled out (15). A 2009 review of available epidemiological studies showed that most studies estimated the prevalence of ASDs to be between $0.6 \%$ and $0.7 \%$ in pre-school and school-age children in Europe and North America (16). Recent studies from the United States (17) and the United Kingdom (15) have demonstrated higher prevalence rates, of $1.1 \%$ and $1.2 \%$, respectively. The ASD prevalence is much higher in boys than in girls. Estimates of male-to-female ratios range from $2: 1$ to $6.5: 1$ (2). The male-to-female ratio is particularly high for socalled high-functioning autistic disorder (autistic disorder with normal-range IQ [IQ $\geq 70]$ ) and Asperger's disorder (2).

\section{Prognosis and developmental outcomes}

The diagnostic stability of ASDs is high for children diagnosed at two years of age, indicating that ASDs are generally lifelong conditions for these children (18). However, children diagnosed at such an early age are likely to be the ones who are more severely affected. The diagnostic stability of ASDs detected at later 
ages, with less severe symptoms, has not been investigated in large population-based study samples. There is no "cure" for ASDs, but there is some evidence that early diagnosis and intervention improve the developmental outcomes (19). Positive prognostic factors are the presence of joint attention skills and functional play skills, the establishment of functional language before the age of five years, and IQ within the normal range $(\geq 70)(1,2)$. Negative prognostic factors are high levels of symptom severity, intellectual disability, absence of functional language at age five years, coexisting epilepsy, and coexisting medical and psychiatric disorders $(1,2)$.

\section{Risk factors}

Genetic factors play a major role in the pathogenesis of ASDs, and the disorder is highly heritable. Most twin studies have estimated the heritability of autistic disorder and ASDs to be between $70 \%$ and $90 \%$ (20), but two recent studies found considerably lower heritability for ASDs in general, at 38\% (21) and 50\% (22), respectively. More research is needed to determine the heritability of ASDs more precisely, but the recent findings indicate that environmental exposures may have a more prominent role than previously assumed.

Conventional genetic diagnostic tools may demonstrate an autism-related genetic variant in up to $20-25 \%$ of individuals with ASDs (23), but this proportion is likely to increase as the diagnostic repertoire expands. The contributing genetic factors appear to be heterogeneous, and a wide variety of genetic markers have been implicated (24). No single genetic variant has been shown to account for more than $1-2 \%$ of the total number of cases (24). This is part of the explanation of why genome-wide association studies have not been very successful at detecting genetic markers of ASDs; genome-wide association studies can only detect associations for alleles occurring with a frequency of $1 \%$ or more in the population. The most promising approach for identifying genetic markers of ASDs is to use the new methods for deep sequencing of DNA that are now becoming available. Studies using exome sequencing, a sequencing method covering the proteincoding regions of DNA (1.5-2\% of the entire genome) have detected a number of potentially causative de novo copy number variants with strong associations with ASDs (25-28).

Most research on environmental risk factors for ASDs points towards pregnancy or early infancy as the critical period. Epidemiological studies have identified a number of prenatal and perinatal exposures associated with an increased risk of ASDs in children. The risk factors with the strongest supporting evidence are (1) advancing paternal age, (2) maternal medication use during pregnancy, (3) maternal infection and immune responses during pregnancy, and (4) birth complications and adverse birth outcomes.

For advancing paternal age, it has been proposed that the association with ASDs is explained by an increase in de novo mutations in children of older fathers (29). For maternal medication use during pregnancy, large-scale studies have found an increase in risk associated with selective serotonin reuptake inhibitors $(30,31)$, other monoamine reuptake inhibitors (31), and valproate (32).

The potential ASD risk associated with maternal infection and immune responses during pregnancy came to light from the follow-up studies of children with congenital rubella syndrome, which showed that high proportions of these children developed autism (33). More recent epidemiological studies have found maternal fever and infection during pregnancy to be associated with increased risk of ASDs in children, but no specific pathogens have been implicated (34). Evidence from animal studies suggests that the deleterious effects of maternal immune responses are mediated by maternal $\mathrm{IgG}$ antibodies reacting with proteins in the fetal brain (34).

The studies of birth complications and adverse birth outcomes differ in terms of exactly which factors are predictive of increased ASD risk. It is also unclear whether these risk factors are potential causes of ASDs or whether the associations could be explained by reverse causation, i.e., that the children's developmental disorders may in fact be the underlying causes - not the consequences - of birth complications and adverse birth outcomes.

Some proportion of ASD cases can probably be explained solely on a genetic basis, but the patterns in which ASDs occur in families suggest that the underlying genetic liabilities for ASDs are often predispositions rather than deterministic causes, and that the pathogenesis may involve interaction between genetic factors and environmental exposures. Furthermore, even in those cases where genetic variants are the only cause, the disease-specific gene variants may in turn be mutations caused by environmental exposures. Consequently, investigations of environmental exposures are crucial to increase our understanding of why ASDs arise and what could potentially prevent them from occurring.

\section{The AUTISM BIRTH COHORT (ABC) STUDY: METHODS AND DESIGN}

\section{Scientific aims}

The following scientific aims were formulated for the ABC Study when the initial grant was obtained from the National Institute of Neurological Disorders and Stroke (NIH/NINDS) in 2003:

1) Establish the Autism Birth Cohort (ABC) through ascertainment of potential ASD cases and selection of controls from the MoBa cohort.

2) Identify environmental factors that may be directly or indirectly associated with ASDs including: prenatal or postnatal infection, mumps-measles-rubella vaccination, very low birth weight and prematurity, other obstetric risk factors in which infections are implicated, and dietary and/or environmental expo- 
sure to methylmercury during pregnancy and postnatal life.

3) Describe the natural history of clinical, anthropometric, and neurobehavioral features of ASDs.

Genetics were not included in the original scientific aims, because the first NINDS grant did not include funding for genetic studies. The intention was to obtain funding for genetic analyses through separate grants later on. An exome sequencing project based on the ABC Study has been funded by the Research Council of Norway and is now ongoing.

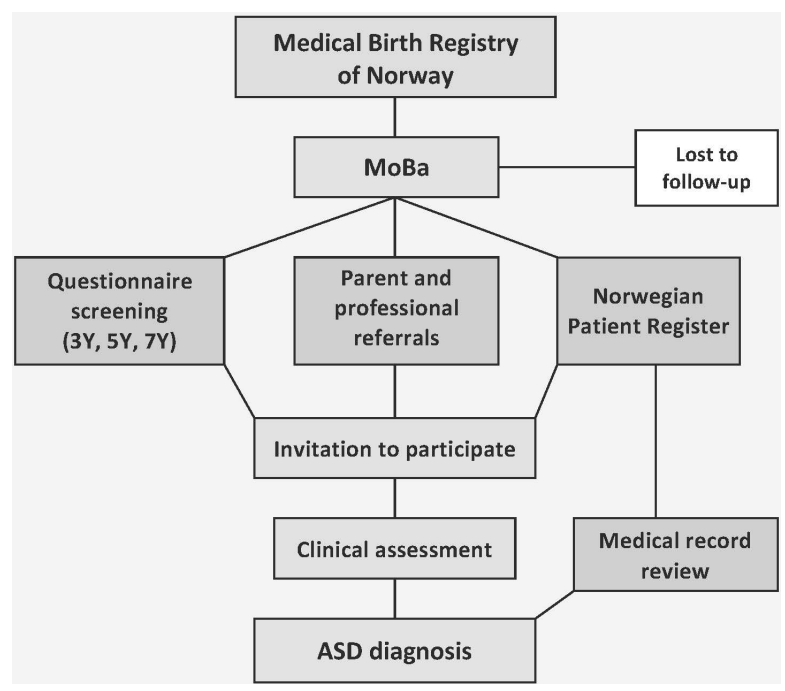

Figure 1. ABC Study: ASD Case Identification. $\mathrm{MoBa}=$ Norwegian Mother and Child Cohort Study. $\mathrm{ABC}=$ Autism Birth Cohort. ASD = Autism spectrum disorder.

\section{Identification of potential ASD cases}

An overview of the case-finding mechanisms of the ABC Study is provided in Figure 1. Cases of ASDs have been identified through (1) questionnaire screening of MoBa mothers at offspring ages three, five, and seven years, (2) professional and parental referrals of children suspected of having ASDs, and (3) linkages to the Norwegian Patient Register (NPR). The screening at three years was implemented for MoBa participants born in February 2002 and later. The $\mathrm{MoBa}$ 36-month questionnaire included the Social Communication Questionnaire (SCQ), a 40-item questionnaire that has previously been validated for ASD screening in clinic-based samples of school-aged children with ASDs (35). The ABC Study used the 33 non-verbal items of the SCQ (the SCQ-33) and other selected questions from the 36-month questionnaire for ASD screening. The screening algorithm was designed to achieve a high sensitivity for ASDs, and also to identify children with disorders that are closely related to ASDs, such as language disorders. The screening in the 5- and 7-year questionnaires was based on direct questions about autistic disorder, Asperger syndrome, and/or autistic traits. The details of the screening procedures are described in Table 1.
Referrals from parents and health professionals were elicited through annual newsletters to $\mathrm{MoBa}$ participants and information on the website of the Norwegian Institute of Public Health (www.fhi.no). Referrals were accepted if the child was a MoBa participant and there was reason to believe the child might have an ASD.

Linkages to the NPR have been conducted annually since 2009, and the ABC Study was the first study to utilize NPR data for research purposes. The NPR collects data on diagnoses from all hospitals and outpatient clinics in Norway, beginning in the year 2008, thereby capturing all children diagnosed with ASDs by Norwegian health services. The NPR contains ICD-10 (3) codes, and potential ASD cases in the ABC Study are $\mathrm{MoBa}$ participants recorded with codes F84.0 (childhood autism), F84.1 (atypical autism), F84.5 (Asperger syndrome), F84.8 (other PDD), or F84.9 (PDD, unspecified).

\section{ASD case ascertainment}

When a child with ASD or potential ASD was detected through any of the mechanisms described above, he/she was invited to participate in a clinical assessment that included the ADI-R (5) and the ADOS (6). These instruments were not available in Norwegian prior to the inception of the ABC Study, so they were translated from the original English versions by authorized translators. The primary purpose of the clinical assessment was to determine whether the child had ASD or not, and the secondary purpose was to collect information about phenotypic characteristics that may distinguish between subtypes of ASDs. The components of the clinical assessment are described in Tables 2-3. The assessments were conducted without knowledge of previous questionnaire responses. Diagnostic conclusions were best-estimate clinical diagnoses derived from test and interview results and from information collected from parents and teachers. The diagnoses were based on DSM-IV-TR (4) criteria, and the ASD case definition included codes 299.00 (autistic disorder), 299.80 (Asperger's disorder), and 299.80 (PDD-NOS).

The characterization of ASD cases that have not been clinically assessed will occur through medical record reviews. The data collected through this review are described in Table 4. The review will be completed by evaluating whether the DSM-IV criteria for any of the subtypes of ASDs are met. The ABC Study will continue to use the DSM-IV criteria, but the data collected will enable a future change to the DSM-5 criteria if needed.

\section{Selection of controls}

For the analyses based on questionnaire and registry data the entire $\mathrm{MoBa}$ cohort is used as the control sample. For the biological analyses, an ABC-specific control group has been established for which the $\mathrm{MoBa}$ biological materials from children and parents are reserved for use by the ABC Study. Controls were 
Table 1. ABC Study: ASD Screening Procedures.

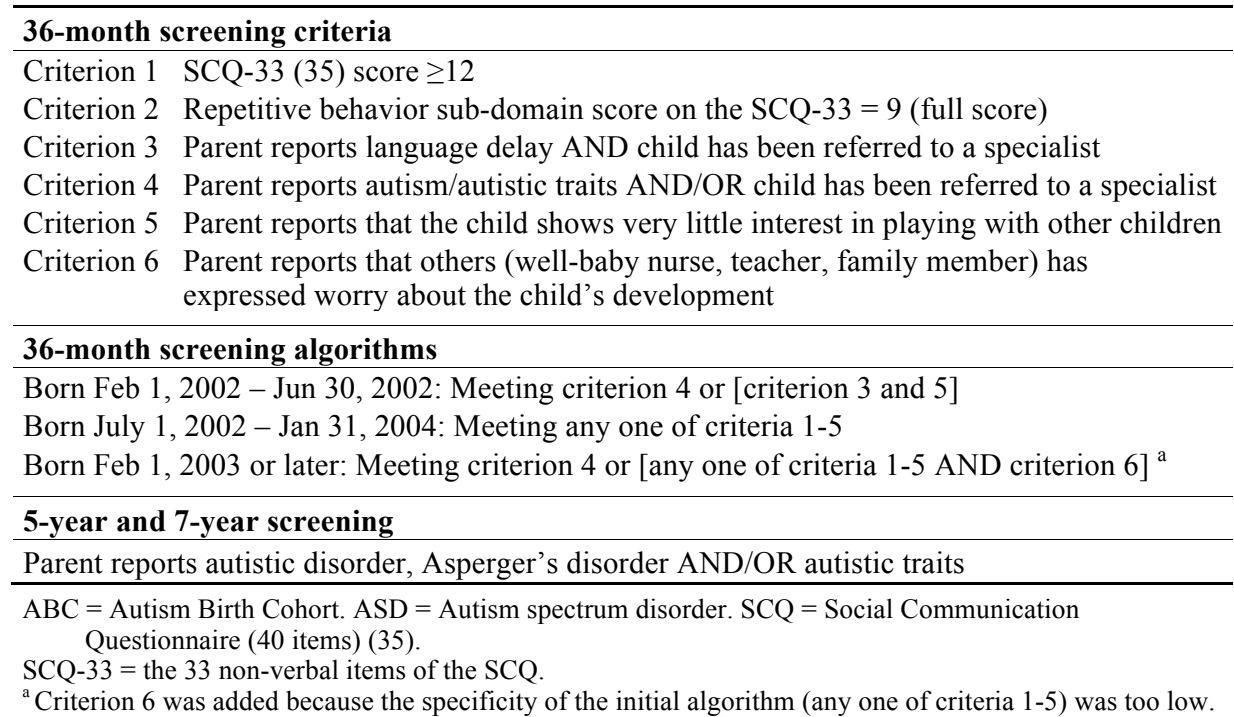

Table 2. ABC Study: Clinical Assessment Components.

\begin{tabular}{l|l|l}
\hline Dimension & Standardized instrument & Mode \\
\hline ASD symptoms & Autism Diagnostic Interview - Revised (ADI-R) (5) & Parent interview \\
\hline ASD symptoms & Autism Diagnostic Observation Schedule (ADOS), First Edition (6) & Child structured observation \\
\hline \multirow{2}{*}{ Cognitive function } & $\begin{array}{l}\text { Children aged 3-5 years: } \\
\text { Stanford-Binet Intelligence Scale, } 5^{\text {th }} \text { Ed. (SB-5) (60) }\end{array}$ & $\begin{array}{l}\text { Children aged } \geq 6 \text { years: } \\
\text { Wechsler Abbreviated Scale of Intelligence (WASI) (61) }\end{array}$ \\
\cline { 2 - 3 } & $\begin{array}{l}\text { Children too low-functioning for SB-5/WASI: } \\
\text { Mullen Scales of Early Learning (62) }\end{array}$ & Child test \\
\hline Language function & $\begin{array}{l}\text { Vineland Adaptive Behavior Scales (VABS) (63), communication sub- } \\
\text { domain }\end{array}$ & Child test \\
\hline Motor function & Pullen Scales of Early Learning (62), motor domain & Child test \\
\hline
\end{tabular}

Other assessment components

Physician history-taking: Full medical and developmental history

Physical examination: Neurological function, dysmorphic traits

Photography: Frontal and side photos of head, photos of skin lesions (if any)

Anthropometric measurements: Length, weight, head circumference

$\mathrm{ABC}=$ Autism Birth Cohort. $\mathrm{ASD}=$ Autism spectrum disorder.

selected before ASD cases were identified, so that everyone was eligible to become a control and the control group is representative of the whole cohort. The sampling was done every other week on those who had attained 37.5 months of age in the two preceding weeks, and the sampling algorithm was designed to capture $1.63 \%$ of MoBa participants on average. About half of these selected controls were invited to participate in the clinical assessment (two or three per calendar week).

\section{Ethical, legal, and social aspects}

The ABC Study has a permit from the Norwegian Data Inspectorate and approvals from the Regional Committee for Medical and Health Research Ethics for Southeastern Norway and the Institutional Review Board at Columbia University.

MoBa participants who were invited to participate in the clinical assessments of the ABC Study received a separate invitation brochure that contained information about the scientific rationale for the study, the collaborators involved, and the content of the clinical assessment. They were informed that participation was voluntary and that their choice would not have any influence on their continuing participation in MoBa. Participation in the assessment required written consent by the parents.

For ASD cases and selected controls who did not participate in the clinical assessment, the use of data and biological materials rests upon the broad consent signed upon recruitment to MoBa. This broad consent was based on an information brochure describing the MoBa data collection and what the consent entailed. The initial information brochure has been followed up by annual newsletters to all MoBa participants and by specific newsletters to participants in various MoBa 
Table 3. ABC Study: Pre-Assessment Forms (Parents and Teachers).

\begin{tabular}{|c|c|}
\hline Dimension & Standardized instrument \\
\hline Psychiatric difficulties ${ }^{\text {a }}$ & $\begin{array}{l}\text { Children aged 3-years: } \\
\text { Early Childhood Inventory - version } 4 \text { (ECI-4) }(64,65) \\
\text { Children aged } \geq 6 \text { years: } \\
\text { Child Symptom Inventory - version } 4 \text { (CSI-4) }(66)\end{array}$ \\
\hline Language function & Child Development Inventory (CDI) (67) \\
\hline Executive function & $\begin{array}{l}\text { Behavior Rating Inventory of Executive Function (BRIEF) }(68,69) \\
\text { Preschool version for ages } 3 \text {-years, regular version for ages } \geq 6 \text { years }\end{array}$ \\
\hline Temperament & Parents only: Child Behavior Questionnaire (CBQ) $(70,71)$ \\
\hline Play and social interaction & Teachers only: Preschool Play Behavior Scale (PPBS) (72) \\
\hline
\end{tabular}

Table 4. ABC Study: Medical Record Review.

\begin{tabular}{l|l}
\hline Dimension & Data collected \\
\hline Referral and assessment history & Time of referral, examinations performed, time of ASD diagnosis \\
\hline ASD symptoms & $\begin{array}{l}\text { Autism Diagnostic Interview - Revised (ADI-R) (5): } \\
\text { Full scores if available, otherwise algorithm scores } \\
\text { Autism Diagnostic Observation Schedule (ADOS) (6): } \\
\text { Full scores if available, otherwise algorithm scores }\end{array}$ \\
\hline Cognitive function & Any test result available \\
\hline Language function & Any test result/parent interview available \\
\hline Executive function & Any test result/parent interview available \\
\hline Adaptive function & Any test result/parent interview available \\
\hline $\begin{array}{l}\text { Other psychiatric and neuro- } \\
\text { developmental disorders }\end{array}$ & Other ICD-10 diagnoses recorded \\
\hline DSM-IV criteria & Evaluation of whether criteria are met for any of the subtype diagnoses of ASDs \\
\hline
\end{tabular}

$\mathrm{ABC}=$ Autism Birth Cohort. $\mathrm{ASD}=$ Autism spectrum disorder.

sub-studies. Information about the ABC Study has been included in all annual MoBa newsletters since 2005. The 2013 edition of the newsletter included a thorough description of the genetic analyses planned in MoBa sub-studies, including the ABC Study. In 2013, the ABC Study also published a separate newsletter with an overview of the study results and the future plans for the study. This ABC-specific newsletter went out to everyone who had participated in the clinical assessments, to ASD cases identified from the NPR, and to all selected controls who had not been clinically assessed.

The ABC Study was the first Norwegian study to use deep sequencing of DNA for research purposes. Exome sequencing is the sequencing of protein-coding regions of DNA, which constitute $1.5-2 \%$ of the entire genome. In 2012, the Norwegian Biotechnology Advisory Board (36) filed a complaint against the $\mathrm{ABC}$ Study, arguing that exome sequencing may generate incidental findings that could potentially have a large impact on participant's lives and that participants were not aware of this risk when they donated their blood samples. A year later, in 2013, a medical geneticist at the Haukeland University Hospital in Bergen published a book in which the ABC Study was prominently featured and heavily criticized on these grounds (37). Due to these controversies, the exome sequencing project went through an additional review by the National Committee of Medical and Health Research Ethics, which resulted in a confirmation of the ethics approval for the project. A number of other MoBa-based exome sequencing projects have now been initiated and approved. The MoBa consent is considered to be a legally and ethically valid foundation for these projects.

\section{RESULTS OF ABC CASE-FINDING PROCEDURES}

\section{Current status}

The number of ASD cases identified, by source of identification, is shown in Table 5. By the end of 2012, there were 518 ASD cases in MoBa, of whom 195 (38\%) had been diagnosed through the clinical assessments while the remaining $323(62 \%)$ had ASD diagnoses assigned by regular health services (12 of these children were assessed by the ABC study at age three years and did not meet the diagnostic criteria for ASD at that time). Of the 518 ASD cases, there were 208 with autistic disorder, 122 with Asperger's disorder, and 188 with PDD-NOS. The male-to-female ratio for ASDs is 4.7 (95\% confidence interval, 4.3-5.2). For MoBa participants born in 2003 and earlier (aged 9 years and older at the end of follow-up), the overall ASD prevalence is now $0.7-0.8 \%$, which is in line with the nationwide prevalence estimates for Norway (38). 
Table 5. ABC Study: Sources of Identified ASD Cases.

\begin{tabular}{|c|c|c|c|c|c|c|c|}
\hline \multirow[b]{2}{*}{ Source } & \multirow{2}{*}{$\begin{array}{c}\text { Total } \\
\mathbf{n}\end{array}$} & \multicolumn{2}{|c|}{ Invited } & \multicolumn{2}{|r|}{ Assessed } & \multicolumn{2}{|c|}{ ASD } \\
\hline & & $\mathbf{n}$ & $\%$ of total & $\mathbf{n}$ & $\%$ participation & $\mathbf{n}$ & PPV (ASD) \\
\hline 36-month screening ${ }^{\mathrm{a}}$ & 873 & 873 & 100 & 450 & 52 & 62 & 14 \\
\hline 5- and 7-year $\mathrm{Q}^{\mathrm{b}}$ & 81 & 81 & 100 & 40 & 49 & 19 & 48 \\
\hline Referrals & 83 & 83 & 100 & 78 & 94 & 46 & 58 \\
\hline NPR $2008-2011$ & 215 & 215 & 100 & 61 & 28 & 58 & 95 \\
\hline Controls & 1811 & 920 & 51 & 368 & 40 & 3 & 0.8 \\
\hline Twins ${ }^{d}$ & 53 & 53 & 100 & 24 & 47 & 0 & 0 \\
\hline Siblings ${ }^{\mathrm{e}}$ & 11 & 11 & 100 & 11 & 100 & 7 & 64 \\
\hline Subtotal & 3127 & 2236 & 72 & 1032 & 46 & 195 & 19 \\
\hline NPR non-validated ASD & 323 & $\mathbf{0}$ & $\mathbf{0}$ & $\mathbf{0}$ & $\mathbf{0}$ & 323 & --- \\
\hline Total & 3450 & 2236 & 65 & 1032 & 46 & 518 & --- \\
\hline
\end{tabular}

Updated per December 31, 2012.

$\mathrm{ABC}=$ Autism Birth Cohort. $\mathrm{ASD}=$ Autism spectrum disorder. PPV $=$ Positive predictive value.

${ }^{a}$ This refers to the original and revised screening algorithms combined. PPV(ASD) for the original algorithm was $11 \%$, whereas the $\mathrm{PPV}(\mathrm{ASD})$ for the revised algorithm is $17 \%$.

${ }^{\mathrm{b}}$ This refers to the children who were detected and invited on the basis of the 5- and 7-year questionnaires. A lot more reported ASDs in these questionnaires but were already detected via other routes.

${ }^{\mathrm{d}}$ If any of the invited children (including the controls) had a twin, the twin was also invited.

${ }^{\mathrm{e}}$ Siblings were assessed if there was reason to suspect ASD.

If these figures hold for the entire cohort, we expect to identify 800-900 ASD cases by the time the whole MoBa population has reached ten years of age in 2019.

\section{Screening results}

The questionnaire-based screening for ASDs did not turn out as planned, for several reasons. First, the questionnaire response rates were lower than expected: $59 \%$ for the 36-month questionnaire, $53 \%$ for the 5 year questionnaire, and $54 \%$ for the 7 -year questionnaire. Second, a lot of invited screen-positives chose not to participate in the clinical assessment, as shown in Table 5; the proportions accepting invitations were $52 \%$ for 36 -month screen-positives and $49 \%$ for children identified from to the 5- and 7-year questionnaires. Third, it soon became apparent that both the sensitivity and the specificity of the 36-month screening algorithm (Table 1) were too low. To limit the number of false positives, an additional step was added to the 36month screening algorithm for children born in 2004 and later: a question about whether others had expressed worry for the child's development. After the revision, children were only defined as screen-positive if meeting one of the five initial criteria AND having a positive response to the worry question (Table 1). This revision improved specificity considerably, but came at the cost of reducing sensitivity. The current sensitivity estimate for the revised algorithm is $36 \%$, and the specificity estimate is $99 \%$. The positive predictive value for ASD was $11 \%$ with the initial algorithm, but increased to $17 \%$ with the revised algorithm.

It also became clear that some children cannot be reliably diagnosed with ASD at an early age even if they do have the disorder. There were a number of children who were screen-positive and clearly had signs of ASDs at age three but for whom there was not enough evidence to justify a diagnosis at that age. Some of those children have later been diagnosed with
ASDs by the ordinary healthcare system (12 children at present).

\section{Registry linkages}

Questionnaire-based screening was originally intended to be the major source of ASD cases in the ABC Study, but as shown in Table 5, the overwhelming majority has been identified through the NPR. Our experiences from the NPR linkages show that the technical aspects of data collection from healthcare institutions work well and that the validity of the diagnoses appears to be high for ASDs overall. Of the 61 ASD cases who participated in the clinical assessment after having been detected through the NPR, 58 were found to meet the DSM-IV criteria for ASDs, generating a positive predictive value (PPV) of 95\% [95\% CI, 86-99\%]. This PPV estimate should be interpreted with caution, however, given the low participation rate among those who were invited. Future record-based validation of the remaining NPR diagnoses is required to determine the validity more precisely.

\section{ABC-BASED RESEARCH GRANTS AND PUBLISHED RESULTS}

\section{ASD case identification and ascertainment}

The initial methods paper describing the ABC Study was published in 2010 (39). The first analysis of ASD prevalence in Norwegian children, based on the first three years of data from the NPR, came out in 2012 (38). This article also included prevalence estimates for ADHD, epilepsy, and cerebral palsy. In 2013, we published a study of whether analyses of ASD risk factors in MoBa and the ABC Study are likely to be affected by selection bias (40). We investigated six selected exposure-disease associations for which we were able to replicate the analyses in a registry-based data set including the entire Norwegian child popula- 
tion. This study was modelled on the previous article about selection bias in $\mathrm{MoBa}$ (41), and the conclusion was similar: there were no substantial differences between MoBa and Norway as a whole, indicating that analyses of risk factors in the ABC Study will not be affected by selection bias (40).

The first article about early ASD screening was published in 2014 (42). This publication investigated the ability of the Modified Checklist for Autism in Toddlers (M-CHAT) (43) to predict the development of ASDs in children. The M-CHAT is an established 23-item screening instrument for ASDs designed for use in children aged 16-30 months (43). The M-CHAT items were embedded in the MoBa 18-month questionnaire. Two different cut-off levels have been proposed for the M-CHAT (43), and our analyses showed that neither of them performed well, with a sensitivity of $20.8 \%$ and $34.1 \%$, respectively (42). In other words, the M-CHAT failed to identify the majority of children with ASDs at 18 months of age. Specificity was also low, with large numbers of normally developed children scoring above cut-off levels (42). Our conclusion was that ASD screening at 18 months of age does not appear to work well (42).

\section{Maternal nutrition in pregnancy}

An insufficient supply of micronutrients during pregnancy is hypothesized to put the fetus at increased risk of neurodevelopmental disorders later in life. Women exposed to famine during early pregnancy have an increased risk of having children with schizophrenia, and this is thought to result from a lack of essential micronutrients $(44,45)$. In the early 1990 s, it was demonstrated that maternal supplementation of folic acid (vitamin B9) in early pregnancy prevents against neural tube defects in children (46), which led to the recommendation that all women planning to get pregnant should start taking folic acid at least one month before conception (47). A case-control study from California recently found that women who took folic acid supplements in pregnancy had a decreased risk of having children with ASDs (48).

In our analyses based on MoBa and the ABC Study, we found that maternal use of folic acid during the time interval from 4 weeks before to 8 weeks after the start of pregnancy reduced the child's risk of severe language delay at age three years by $45 \%$ (49). Severe language delay is one of the core symptoms of ASDs, and it is also a feature of most other severe neurodevelopmental disturbances in children. Laboratory analyses showed good agreement between maternal self-report of supplement use and the levels of folate measured in their plasma samples (50). The article about language delay was followed by another one about ASDs specifically, in which we found a similar reduction in risk for autistic disorder among children whose mothers used folic acid (51). The adjusted odds ratio of autistic disorder was 0.61 (95\% confidence interval, 0.41-0.90) in children of folic acid users compared to children of non-users (51). The reduction in risk was limited to those who had used folic acid in early pregnancy; no reduction was observed for those who started after week 8 of pregnancy (51). There was no reduction in ASD risk associated with other dietary supplements (51). Our findings do not establish a causal relation between folic acid and ASD risk, but they do support current recommendations of folic acid supplementation. If this were to represent a causal biological mechanism, folic acid would be the first preventive measure identified against ASDs.

In analyses of nationwide health registry data, we showed that a short interval between pregnancies is associated with an increase in risk of autistic disorder in the later-born child (52). This has also been shown previously (53), and the association is hypothesized to result from a depletion of micronutrients in mothers with closely spaced pregnancies $(52,53)$. Consequently, the finding provides further support for the hypothesis that folate and folic acid affect children's risk of ASDs.

\section{Parental overweight and obesity}

Maternal obesity is another known risk factor for neurodevelopmental disorders in children. A previous study from California found an increase in risk of ASDs in children whose mothers were obese (body mass index $\geq 30$ ) before the start of pregnancy (54). Our analyses in MoBa and the ABC Study confirmed these findings for autistic disorder and Asperger's disorder (55). However, the associations with maternal obesity were substantially weakened by adjustment for paternal body mass index, and paternal obesity turned out to be a stronger and more robust risk factor than maternal obesity (55). There appears to be a doseresponse relation, with an exponential increase in ASD risk by increasing paternal BMI (55). We do not know why overweight and obesity in the father might increase the risk of ASD in the child, but potential explanations may be through genetic associations or through epigenetic alterations induced by paternal obesity (55). However, our analyses need to be replicated in other study samples before paternal obesity may be declared as a risk factor for ASDs, and the risk associated with paternal obesity should be studied for other neurodevelopmental disorders as well.

\section{Early child growth}

The first article published under this aim was a study of early growth trajectories in ASDs (56). Previous studies, mainly from clinic-based study samples, have shown an increase in head growth in the first year of life in children with ASDs, and increased head size has been proposed to be an early biomarker of ASD (57). Our analyses based on MoBa and the ABC Study did not replicate these findings: boys with ASDs had similar mean head circumference to other boys, although there was a trend towards an increase in macrocephaly at 12 months of age. Girls with ASDs actually had a smaller head size on average. We believe the discrepancy between our findings and those of previous 
studies can be explained by differences in recruitment and case ascertainment - population-based recruitment is likely to bring in a wider range of ASD cases that are more representative of the autism spectrum as a whole. Our findings do not negate those of previous studies, but they do indicate that increased head growth is not a generally applicable biomarker for ASDs in children.

\section{FUTURE PLANS FOR THE ABC STUDY}

\section{Analyses of plasma and RNA samples}

In the years to come, the majority of research funds will be allocated to analyses of biological materials, which is where the ABC Study really is poised to make novel contributions. No other cohort has an array of biological samples comparable to that of $\mathrm{MoBa}$. $\mathrm{MoBa}$ is unique in including full family trios, and the cohort is the only one in which analyses of DNA, RNA and plasma can be integrated. All the biological samples were collected during the fetal period or right after the child's birth, which is when the pathogenesis of ASDs is most likely to be occurring.

Analyses of plasma and RNA samples will be conducted by the Center for Infection and Immunity at the Mailman School of Public Health, Columbia University. These analyses will be performed on plasma samples from mothers, fathers and children, and RNA samples from children's cord blood. The results will be combined with genetic data to investigate geneenvironment interactions. The following will be investigated:

- Prenatal and perinatal microbial exposures

- Maternal and child innate immune and inflammatory responses

- Maternal and child biomarkers of autism risk (proteomics and metabolomics)

- Prenatal and postnatal exposure to xenobiotics (heavy metals, organic compounds)

\section{Genetic analyses}

Exome sequencing has been performed on 200 family trios (children, mothers and fathers) of ASD cases identified through the ABC Study. The sequencing has been performed at the Wellcome Trust Sanger Institute in Cambridge in the United Kingdom, and the data are now undergoing analysis. The goal is to eventually conduct exome sequencing on all the ASD children and their parents and to combine the exome data with similar data for other neurodevelopmental disorders.

\section{Analyses of deciduous teeth}

These analyses will utilize deciduous teeth collected by the MoBa tooth biobank. A laboratory has not been chosen for the analyses, but the intention is to investigate whether ASD risk is associated with pre- and postnatal exposure to heavy metals, acetaminophen, ibuprofen and/or semi-volatile organic compounds.

\section{Other ongoing analyses}

Results of the 36-month screening for ASDs will be published when the medical record reviews have been completed for ASD cases detected through the NPR. Other ongoing studies are investigating comorbid psychiatric and gastrointestinal disorders in children with ASDs and patterns of medication use in these children. It is well known that psychiatric and gastrointestinal comorbidity is common among children with ASDs, but there is little data available from population-based study samples.

\section{International collaboration}

As a result of our work in the ABC Study, the ABC Study collaborators were invited to participate in the International Collaboration for Autism Registry Epidemiology (iCARE) from 20092013 (58). This collaboration was funded by the American research foundation Autism Speaks and included health registries from six countries: Denmark, Sweden, Finland, Norway, Israel and Western Australia. In 2013, iCARE was succeeded by the Multigenerational Familial and Environmental Risk for Autism (MINERvA) Network, which is funded by the Eunice Kennedy Shriver National Institute of Child Health and Development and includes the six iCARE countries plus the statewide California autism registry. Until now Norway has only contributed nationwide health registry data to these collaborations, but we do aim to also use MoBa and $\mathrm{ABC}$ data in international collaborations in the future. It would be particularly useful to combine $\mathrm{MoBa} / \mathrm{ABC}$ data with data from comparable child cohorts such as the Danish National Birth Cohort (59).

\section{Collaboration with other studies of neuro- developmental disorders in $\mathrm{MoBa}$}

Since the initiation of the ABC Study, several other studies of neurodevelopmental disorders have been established in MoBa. The ABC Study investigators will contribute to coordinate analyses of risk factors and developmental trajectories across disorders, particularly with regards to analyses of biological samples.

\section{Future data collection}

The current data collection grant from the NINDS expires in 2015. In the years to come, the priority will be the analyses of data and biological samples that have already been collected, but we will continue the identification and follow-up of ASD cases through annual linkages with the NPR. All new ASD cases will subsequently be confirmed and characterized through medical record reviews.

\section{ACKNOWLEDGEMENTS}

The data collection of the ABC Study is funded by the National Institute of Neurological Disorders and Stroke (NIH/NINDS), grant no. NS47537 (Lipkin). The study is conducted in collaboration between the Norwegian Institute of Public Health, the Mailman School of Public Health at Columbia University, and the NINDS. The writing of this publication was supported by the Oak Fellowships Programme in Molecular and Environmental Epidemiology, grant no. OCAY-12-326. 


\section{REFERENCES}

1. Diagnostic and Statistical Manual of Mental Disorders, Fifth Edition. Arlington, VA: American Psychiatric Association, 2013.

2. Johnson CP, Myers SM. Identification and evaluation of children with autism spectrum disorders. Pediatrics 2007; 120 (5): 1183-215.

3. International Classification of Diseases, 10th Revision. Geneva, Switzerland: WHO, 1990.

4. Diagnostic and Statistical Manual of Mental Disorders, Fourth Edition, Text Revision. Arlington, VA: American Psychiatric Association, 2000.

5. Lord C, Rutter M, Le Couteur A. Autism Diagnostic Interview-Revised: a revised version of a diagnostic interview for caregivers of individuals with possible pervasive developmental disorders. J Autism Dev Disord 1994; 24 (5): 659-85.

6. Lord C, Risi S, Lambrecht L, Cook EH, Jr., Leventhal BL, DiLavore PC, et al. The autism diagnostic observation schedule-generic: a standard measure of social and communication deficits associated with the spectrum of autism. J Autism Dev Disord 2000; 30 (3): 205-23.

7. Kanner L. Autistic disturbances of affective contact. Acta Paedopsychiatrica 1968; 35 (4): 100-36.

8. Frith U. Autism and Asperger syndrome. Cambridge: Cambridge University Press, 1991.

9. Baker JP. Autism at 70 - redrawing the boundaries. N Engl J Med 2013; 369 (12): 1089-91.

10. Lord C, Petkova E, Hus V, Gan W, Lu F, Martin DM, et al. A multisite study of the clinical diagnosis of different autism spectrum disorders. Arch Gen Psychiatry 2012; 69 (3): 306-13.

11. World Health Organization: www.who.int/classifications/icd/en: World Health Organization [cited 5 April 2013].

12. Identifying infants and young children with developmental disorders in the medical home: an algorithm for developmental surveillance and screening. Pediatrics 2006; 118 (1): 405-20.

13. Al-Qabandi M, Gorter JW, Rosenbaum P. Early autism detection: are we ready for routine screening? Pediatrics 2011; 128 (1): e211-7.

14. Blumberg SJ, Bramlett MD, Kogan MD, Schieve LA, Jones JR, Lu MC. Changes in Prevalence of ParentReported Autism Spectrum Disorder in School-aged U.S. Children: 2007 to 2011-2012. National Health Statistics Reports, no. 65. Hyattsville, MD: National Center for Health Statistics, 2013.

15. Baird G, Simonoff E, Pickles A, Chandler S, Loucas T, Meldrum D, et al. Prevalence of disorders of the autism spectrum in a population cohort of children in South Thames: the Special Needs and Autism Project (SNAP). Lancet 2006; 368 (9531): 210-5.

16. Fombonne E. Epidemiology of pervasive developmental disorders. Pediatr Res 2009; 65 (6): 591-8.

17. Prevalence of autism spectrum disorders - Autism and Developmental Disabilities Monitoring Network, 14 sites, United States, 2008. MMWR Surveill Summ 2012; 61 (3): 1-19.

18. Lord C, Risi S, DiLavore PS, Shulman C, Thurm A, Pickles A. Autism from 2 to 9 years of age. Arch Gen Psychiatry 2006; 63 (6): 694-701.

19. Myers SM, Johnson CP. Management of children with autism spectrum disorders. Pediatrics 2007;120 (5): $1162-82$

20. Ronald A, Hoekstra RA. Autism spectrum disorders and autistic traits: a decade of new twin studies. $A m J$ Med Genet [B] 2011; 156B (3): 255-74.

21. Hallmayer J, Cleveland S, Torres A, Phillips J, Cohen B, Torigoe T, et al. Genetic heritability and shared environmental factors among twin pairs with autism. Arch Gen Psychiatry 2011; 68 (11): 1095-102.

22. Sandin S, Lichtenstein P, Kuja-Halkola R, Larsson H, Hultman CM, Reichenberg A. The familial risk of autism. JAMA 2014; 311 (17): 1770-7.

23. Miles JH. Autism spectrum disorders - a genetics review. Genet Med 2011; 13 (4): 278-94.

24. Abrahams BS, Geschwind DH. Advances in autism genetics: on the threshold of a new neurobiology. Nature Rev Genet 2008; 9 (5): 341-55.

25. O'Roak BJ, Deriziotis P, Lee C, Vives L, Schwartz JJ, Girirajan S, et al. Exome sequencing in sporadic autism spectrum disorders identifies severe de novo mutations. Nature Genet 2011; 43 (6): 585-9.

26. Sanders SJ, Murtha MT, Gupta AR, Murdoch JD, Raubeson MJ, Willsey AJ, et al. De novo mutations revealed by whole-exome sequencing are strongly associated with autism. Nature 2012; 485 (7397): 237-41.

27. O'Roak BJ, Vives L, Girirajan S, Karakoc E, Krumm N, Coe BP, et al. Sporadic autism exomes reveal a highly interconnected protein network of de novo mutations. Nature 2012; 485 (7397): 246-50.

28. Neale BM, Kou Y, Liu L, Ma'ayan A, Samocha KE, Sabo A, et al. Patterns and rates of exonic de novo mutations in autism spectrum disorders. Nature 2012; 485 (7397): 242-5.

29. Reichenberg A, Gross R, Weiser M, Bresnahan M, Silverman J, Harlap S, et al. Advancing paternal age and autism. Arch Gen Psychiatry 2006; 63 (9): 1026-32.

30. Croen LA, Grether JK, Yoshida CK, Odouli R, Hendrick V. Antidepressant use during pregnancy and childhood autism spectrum disorders. Arch Gen Psychiatry 2011; 68 (11): 1104-12. 
31. Rai D, Lee BK, Dalman C, Golding J, Lewis G, Magnusson C. Parental depression, maternal antidepressant use during pregnancy, and risk of autism spectrum disorders: population based case-control study. BMJ 2013; 346: f2059.

32. Christensen J, Gronborg TK, Sorensen MJ, Schendel D, Parner ET, Pedersen LH, et al. Prenatal valproate exposure and risk of autism spectrum disorders and childhood autism. JAMA 2013; 309 (16): 1696-703.

33. Chess S. Follow-up report on autism in congenital rubella. J Autism Child Schizophr 1977; 7 (1): 69-81.

34. Braunschweig D, Van de Water J. Maternal autoantibodies in autism. Arch Neurol 2012; 69 (6): 693-9.

35. Berument SK, Rutter M, Lord C, Pickles A, Bailey A. Autism screening questionnaire: diagnostic validity. $\mathrm{Br}$ J Psychiatry 1999; 175: 444-51.

36. Norwegian Biotechnology Advisory Board: http://www.bioteknologiradet.no/english/ [cited 16 July 2014 ].

37. Blinkenberg EØ. Min DNAgbok. Personlig og forståelig om genetikk. Oslo: Cappelen Damm, 2013.

38. Suren P, Bakken IJ, Aase H, Chin R, Gunnes N, Lie KK, et al. Autism spectrum disorder, ADHD, epilepsy, and cerebral palsy in Norwegian children. Pediatrics 2012; 130 (1): e152-8.

39. Stoltenberg C, Schjolberg S, Bresnahan M, Hornig M, Hirtz D, Dahl C, et al. The Autism Birth Cohort: a paradigm for gene-environment-timing research. Mol Psychiatry 2010; 15 (7): 676-80.

40. Nilsen RM, Suren P, Gunnes N, Alsaker ER, Bresnahan M, Hirtz D, et al. Analysis of self-selection bias in a population-based cohort study of autism spectrum disorders. Paediatr Perinat Epidemiol 2013; 27: 553-63.

41. Nilsen RM, Vollset SE, Gjessing HK, Skjaerven R, Melve KK, Schreuder P, et al. Self-selection and bias in a large prospective pregnancy cohort in Norway. Paediatr Perinat Epidemiol 2009; 23 (6): 597-608.

42. Stenberg N, Bresnahan M, Gunnes N, Hirtz D, Hornig M, Lie KK, et al. Identifying children with autism spectrum disorder at 18 months in a general population sample. Paediatr Perinat Epidemiol 2014; 28 (3): 255-62.

43. Robins DL, Fein D, Barton ML, Green JA. The Modified Checklist for Autism in Toddlers: an initial study investigating the early detection of autism and pervasive developmental disorders. J Autism Dev Disord 2001; 31 (2): 131-44.

44. Susser E, Neugebauer R, Hoek HW, Brown AS, Lin S, Labovitz D, et al. Schizophrenia after prenatal famine. Further evidence. Arch Gen Psychiatry 1996; 53 (1): 25-31.

45. St Clair D, Xu M, Wang P, Yu Y, Fang Y, Zhang F, et al. Rates of adult schizophrenia following prenatal exposure to the Chinese famine of 1959-1961. JAMA 2005;294 (5): 557-62.

46. Prevention of neural tube defects: results of the Medical Research Council Vitamin Study. MRC Vitamin Study Research Group. Lancet 1991; 338 (8760): 131-7.

47. Norwegian Directorate of Health. Recommendations of folic acid intake (in Norwegian only): http://helsedirektoratet.no/publikasjoner/folat - forbered-barnet-helse-i-din-kropp/Publikasjoner/folat.pdf 2004 [cited 8 May 2013].

48. Schmidt RJ, Tancredi DJ, Ozonoff S, Hansen RL, Hartiala J, Allayee H, et al. Maternal periconceptional folic acid intake and risk of autism spectrum disorders and developmental delay in the CHARGE (CHildhood Autism Risks from Genetics and Environment) case-control study. Am J Clin Nutr 2012; 96 (1): 80-9.

49. Roth C, Magnus P, Schjolberg S, Stoltenberg C, Suren P, McKeague IW, et al. Folic acid supplements in pregnancy and severe language delay in children. JAMA 2011; 306 (14): 1566-73.

50. Roth C, Bjørke-Monsen AL, Reichborn-Kjennerud T, Nilsen RM, Smith GD, Stoltenberg C, et al. Use of folic acid supplements in early pregnancy in relation to maternal plasma levels in week 18 of pregnancy. Mol Nutr Food Res 2013; 57: 653-60.

51. Suren P, Roth C, Bresnahan M, Haugen M, Hornig M, Hirtz D, et al. Association between maternal use of folic acid supplements and risk of autism spectrum disorders in children. JAMA 2013; 309 (6): 570-7.

52. Gunnes N, Suren P, Bresnahan M, Hornig M, Lie KK, Lipkin WI, et al. Interpregnancy interval and risk of autistic disorder. Epidemiology 2013; 24 (6): 906-12.

53. Cheslack-Postava K, Liu K, Bearman PS. Closely spaced pregnancies are associated with increased odds of autism in California sibling births. Pediatrics 2011;127 (2): 246-53.

54. Krakowiak P, Walker CK, Bremer AA, Baker AS, Ozonoff S, Hansen RL, et al. Maternal metabolic conditions and risk for autism and other neurodevelopmental disorders. Pediatrics 2012; 129 (5): e1121-8.

55. Suren P, Gunnes N, Roth C, Bresnahan M, Hornig M, Hirtz D, et al. Parental obesity and risk of autism spectrum disorder. Pediatrics 2014; 133: 1128-38.

56. Suren P, Stoltenberg C, Bresnahan M, Hirtz D, Lie KK, Lipkin WI, et al. Early growth patterns in children with autism. Epidemiology 2013; 24 (5): 660-70.

57. Courchesne E, Pierce K, Schumann CM, Redcay E, Buckwalter JA, Kennedy DP, et al. Mapping early brain development in autism. Neuron 2007; 56 (2): 399-413.

58. Schendel DE, Bresnahan M, Carter KW, Francis RW, Gissler M, Gronborg TK, et al. The International Collaboration for Autism Registry Epidemiology (iCARE): multinational registry-based investigations of autism risk factors and trends. J Autism Dev Disord 2013; 43 (11): 2650-63. 
59. Olsen J, Melbye M, Olsen SF, Sorensen TI, Aaby P, Andersen AM, et al. The Danish National Birth Cohort its background, structure and aim. Scand J Public Health 2001; 29 (4): 300-7.

60. Roid GH. Stanford-Binet Intelligence Scales (5th ed.). Itasca, IL: Riverside Publishing, 2003.

61. WASI - Wechsler Abbreviated Scale of Intelligence. Manual. Toronto: PsychCorp (Harcourt Assessment/ Pearson Assessment), 1999.

62. Mullen EM. Mullen Scales of Early Learning AGS Edition. Circle Pines, MN: American Guidance Service, 1995.

63. Sparrow S, Balla D, Cicchetti D. Vineland Adaptive Behavior Scales. Circle Pines, MN: American Guidance Services, 1984.

64. Gadow K, Sprafkin J. Early Childhood Inventory 4. Norms manual. Stony Brook, NY: Checkmate Plus Ltd., 1997.

65. Gadow K, Sprafkin J. Early Childhood Inventory 4. Screening manual. Stony Brook, NY: Checkmate Plus Ltd., 2000.

66. Gadow K, Sprafkin J. Child Symptom Inventory 4. Screening and norms manual. Stony Brook, NY: Checkmate Plus Ltd., 2002.

67. Ireton H. Child Development Inventory. Minneapolis, MN: Behavior Science Systems Inc., 1992.

68. Gioia G, Espy K, Isquith P. Behavior rating inventory of executive function - preschool version. Florida: Avn. Lutz Psychological Assessment Resources Inc., 2003.

69. Gioia G, Isquith P, Guy S, Kenworthy L. Behavior rating inventory of executive function - professional manual. Florida: Avn. Lutz Psychological Assessment Resources Inc., 2000.

70. Rothbart MK, Ahadi SA, Hershey KL, Fisher P. Investigations of temperament at three to seven years: the Children's Behavior Questionnaire. Child Dev 2001; 72 (5): 1394-408.

71. Putnam SP, Rothbart MK. Development of short and very short forms of the Children's Behavior Questionnaire. J Pers Assess 2006; 87 (1): 102-12.

72. Coplan R, Rubin K. Exploring and assessing nonsocial play in the preschool: the development and validation of the preschool play behavior scale. Social Development 1998; 7 (1): 72-91.

73. Egger HL, Erkanli A, Keeler G, Potts E, Walter BK, Angold A. Test-Retest Reliability of the Preschool Age Psychiatric Assessment (PAPA). J Am Acad Child Adolesc Psychiatry 2006; 45 (5): 538-49. 